\title{
Neuraminidase Activity in Bacterial Meningitis
}

\author{
Ruchard D. O'Toole, Louise Goode, and Calderon Howe \\ From the Department of Medicine, Univrsity of Washington, the Seattle \\ Veterans Administration Hospital, Seattle, Washington 98108, and the \\ Department of Microbiology, Columbia University College of Physicians \\ and Surgeons, New York 10032
}

A B S T R A C T The relation of neuraminidase to morbidity and mortality was examined in patients with Haemophilus influenzae, meningococcal, and pneumococcal meningitis. Ten strains of $H$. influenzae and eight strains of meningococci from infected cerebrospinal fluid (CSF) did not elaborate neuraminidase. Each of 27 strains of pneumococci from infected CSF elaborated both neuraminidase and $N$-acetylneuraminic acid (NANA) aldolase. There was no correlation between amount of neuraminidase secreted in vitro and survival of patients.

Values for free and total NANA concentrations were derived from admission CSF samples of 63 patients with meningitis; 18 patients infected with Neisseria meningitidis, 10 with $H$. influenzae and 35 with Diplococcus pneumoniae. Mean values for total NANA were elevated in each type of bacterial meningitis; however, abnormal concentrations of free CSF NANA were detected only in 17 patients with pneumococcal meningitis. 11 of 18 patients with pneumococcal meningitis showing normal free CSF NANA concentrations were cured, whereas only 4 patients with abnormal free NANA levels survived without residua. Both coma and bacteremia occurred significantly more often among patients with elevated concentrations of free CSF NANA. The association of elevated concentrations of free CSF NANA with coma and with an adverse prognosis suggested that neuraminidase may be a factor in the pathogenesis of penumococcal meningitis.

\section{INTRODUCTION}

Pneumococci, that are freshly isolated from infected tissue, have been shown to elaborate a neuraminidase (1). The enzyme is secreted during the logarithmic phase of growth and cleaves terminal molecules of $N$ acetylneuraminic acid (NANA) ${ }^{1}$ from glycoproteins and from gangliosides (2-5). If secreted into infected

\footnotetext{
Received for publication 5 August 1970 and in revised form 16 November 1970.

${ }^{1}$ Abbreviations used in this paper: HBSS, Hanks balanced salt solution; NANA, $N$-acetylneuraminic acid.
}

cerebrospinal fluid (CSF), neuraminidase might liberate NANA from exposed substrates such as CSF proteins, gangliosides, and the glycoproteins of neurons and other central nervous system (CNS) tissues. Moreover, if these substrates participate in the regulation of neural activity, molecular alterations induced by enzymatic activity might result in clinical manifestations of neuronal dysfuncton (6-7).

This study was undertaken to quantify the production of neuraminidase by pneumococci isolated from patients with meningitis, to assess the activity of the enzyme during infection by quantification of free and total CSF NANA, and to correlate these data with results of therapy in 35 patients with pneumococcal meningitis.

\section{METHODS}

Serum and CSF were collected from 36 patients with pneumococcal meningitis and from 14 of 22 patients with meningococcal meningitis. These patients comprised the majority of cases studied in Calcutta, India, during 1966 and 1967, to ascertain the effects of methylprednisolone in the treatment of bacterial meningitis (8). Patients were selected for steroid therapy in a double-blind, block-randomized manner, and received a total dose of $1500 \mathrm{mg}$ methylprednisolone during the first 4 days in hospital. Lumbar punctures were performed on days 1,3 (48 hr after admission), 5, 7, and 14 of treatment in order to assess the effects of the drug. $\mathrm{CSF}$ and serum samples were stored at $-20^{\circ}$ or $-60^{\circ} \mathrm{C}$ following the addition of $0.1 \%$ sodium azide as preservative. For a period of 6 months in 1967 , they were stored at $4^{\circ} \mathrm{C}$. Patients were selected for analysis solely according to the availability of a portion of acute phase CSF for NANA determinations. Patients ranged in age from 1 to $74 \mathrm{yr}$ but only three were less than $6 \mathrm{yr}$ old.

Pneumococci were isolated from CSF and identified by colonial morphology, sensitivity to ethylhydrocuprein, and bile solubility. They were typed with rabbit antiserum and stored in the lyophilized state or in undiluted rabbit blood at $-70^{\circ} \mathrm{C}$ until studied. Meningococci were identified by morphology on Gram stain, peroxidase production, and pattern of sugar fermentation.

Four strains of meningococci isolated from U. S. Army recruits with meningitis in 1969 were typed serologically and stored at $-70^{\circ} \mathrm{C}^{2}$ Portions of acute phase CSF and

\footnotetext{
${ }^{2}$ Kindly provided by Dr. George Counts.
} 
the causative agents from 10 patients with Haemophilus influenzae and 4 patients with meningococcal meningitis were obtained from Childrens Orthopedic Hospital, Seattle. Samples of $H$. influenzac were identified by colonial morphology and by $\mathrm{X}$ and $\mathrm{V}$ factor growth requirements. They were typed with commercial antiserum (Hyland Laboratories, Inc., Los Angeles, Calif.). Patients with $H$. influenzac meningitis ranged in age from 6 months to $6 \mathrm{yr}$ and those with meningococcal disease ranged from 1 to 25 with a mean of $14 \mathrm{yr}$ of age.

Meningococci and $H$. influenzae obtained in Seattle were tested for neuraminidase production within 10 days of isolation or immediately following removal from storage at $-70^{\circ} \mathrm{C}$. CSF obtained in Seattle was maintained at $4^{\circ} \mathrm{C}$ following removal of leukocytes by centrifugation and tested for NANA within $3 \mathrm{wk}$ of the onset of meningitis.

Controls consisted of patients subjected to lumbar puncture for reasons other than suspicion of acute bacterial meningitis. Nine patients from the Seattle Veterans Hospital ranged in age from 21 to $58 \mathrm{yr}$ and 19 patients from Childrens Orthopedic Hospital ranged from 2 months to 10 yr of age.

Enzy'me assays. Pneumococci were grown in Todd-Hewitt broth (Difco) and meningococci were cultured in Mueller-Hinton broth which contained $1 \%$ enrichment additive (ISOVITALEX, Isovitalex, Baltimore Biological Laboratories, Cockeysville, Md.). Hemoglobin was added to this medium at a concentration of $1 \%$ for cultivation of $H$. influenzae.

Pneumococcal cultures were incubated aerobically at $37^{\circ} \mathrm{C}$ for $16 \mathrm{hr}$ and viable organisms in each culture were estimated by inspection of pour plates containing $3 \%$ defibrinated rabbit blood. Broth cultures were centrifuged at $700 \mathrm{~g}$ for $30 \mathrm{~min}$ at $4^{\circ} \mathrm{C}$, and portions of the supernatant broth were stored at $-20^{\circ} \mathrm{C}$ and tested 6 wk later.

Meningococci and $H$. influenzae were inoculated into 250 $\mathrm{ml}$ portions of medium and incubated at $37^{\circ} \mathrm{C}$ in an atmosphere of $10 \% \quad \mathrm{CO}_{2}$ for $24 \mathrm{hr}$. Abundance and purity of growth were confirmed by subculture on chocolate agar. Bacteria were removed by centrifugation at $700 \mathrm{~g}$ in the cold and protein was precipitated at $75 \%$ saturation with ammonium sulfate. Precipitates were taken up in small vol of distilled water such that nondialyzable bacterial proteins were concentrated 10 - to 25 -fold and then dialyzed in the cold against repeated changes of distilled water. $0.2 \mathrm{ml}$ of this concentrate was incubated at $37^{\circ}$ with $2.5 \mathrm{mg}$ human alpha-1-acid glycoprotein (Calbiochem, Los Angeles, Calif. 90063 ), which had been dissolved in $0.8 \mathrm{ml}$ of $0.15 \mathrm{M} \mathrm{NaCl}$ and buffered to $\mathrm{pH} 6.5$ with $0.015 \mathrm{~m}$ phosphate, as substrate. After $60 \mathrm{~min}$ incubation, duplicate $0.4 \mathrm{ml}$ samples were taken from the reaction mixture and analyzed for free NANA by the thiobarbituric acid assay of Warren with saline containing substrate as a negative control and crystalline NANA (Koch-Light Labs Ltd., Colnbrook, Buckinghampshire, England) as the standard (9).

$0.6 \mathrm{ml}$ portions of pneumococcal culture supernatants were analyzed with the same reagents except that $1.25 \mathrm{mg}$ glycoprotein was dissolved in $2.4 \mathrm{ml}$ of phosphate-buffered saline. Duplicate samples were assayed after $80 \mathrm{~min}$ incubation at $37^{\circ}$ with Todd-Hewitt broth containing substrate as a negative control. Aldolase activity was assayed by the formation of $N$-acetyl-D-mannosamine according to the method of Brunetti, Jourdian, and Roseman (10). $0.5 \mathrm{ml}$ portions of the reaction mixture were analyzed in duplicate

\footnotetext{
${ }^{3}$ Generously provided by Mrs. M. Meyer.
}

using Todd-Hewitt broth containing substrate as the negative control and $N$-acetyl-D-mannosamine (Sigma Chemical Co., St. Louis, Mo.) as the standard.

Duplicate $0.4 \mathrm{ml}$ portions of $\mathrm{CSF}$ were tested for the presence of free NANA and values for total NANA were derived from $0.4 \mathrm{ml}$ samples of CSF which were hydrolyzed for $1 \mathrm{hr}$ at $80^{\circ} \mathrm{C}$ with $0.05 \mathrm{ml}$ of $1 \mathrm{~N}$ sulfuric acid. Each sample was read at 532 and $549 \mathrm{~m} \mu$ and corrected for interfering chromogens as described by Jakoby and Warren (11). Statistical analysis was performed according to standard procedures (12).

Enzyme neutralization test. A purified pneumococcal neuraminidase ${ }^{*}(13)$, was diluted in $0.15 \mathrm{M} \mathrm{NaCl}$ and buffered to $\mathrm{pH} 6.0$ with $0.015 \mathrm{M}$ phosphate such that $0.2 \mathrm{ml}$ of the enzyme solution, when incubated with $0.2 \mathrm{ml}$ collocalia mucoid (14) at $37^{\circ} \mathrm{C}$ for $60 \mathrm{~min}$, and assayed for free NANA by the Warren method, produced an absorbance reading, corrected for a substrate blank, of 0.25 at $549 \mathrm{~m} \mu$. To serial dilutions of serum and CSF, in a volume of $0.5 \mathrm{ml}, 0.2 \mathrm{ml}$ of this enzyme preparation was added. After mixing, we allowed the tubes to stand for $30 \mathrm{~min}$ at room temperature. $0.2 \mathrm{ml}$ portions of collocalia mucoid were then added to each of the tubes and incubated for $60 \mathrm{~min}$ at $37^{\circ} \mathrm{C}$. Duplicate $0.2 \mathrm{ml}$ samples of each reaction mixture were then read at $549 \mathrm{~m} \mu$. As controls, dilutions of CSF and serum were incubated separately with substrate in saline. Dilutions of CSF and serum showing a reduction of $50 \%$ or more in liberation of NANA, as compared with the positive control, were considered to show specific enzyme inhibition.

\section{RESULTS}

One patient with meningococcal meningitis died; however, none of those with Haemophilus influenzae meningitis died or had residual neurologic defects. Of 35 patients with pneumococcal meningitis 15 were cured, 16 died, 2 had severe residual dementia, another became deaf, and 1 had multiple neurologic deficits and relapsed when treatment was discontinued. One patient was excluded from the analysis because the reason for his death was obscure and could not be attributed to meningitis. 5 of the 16 patients who died survived the acute phase of the illness and showed significant reduction of CSF abnormalities. However, each patient sustained severe brain damage and died after 5 to 15 days with no improvement in neurologic status. Administration of steroids affected the time of death of patients with pneumococcal meningitis but did not influence survival rates or rate of return toward normal of CSF leukocyte counts, protein concentrations, or NANA levels (8).

Enzyme activity. 10 strains of Haemophilus infuenzae, type b, and 8 strains of Neisseria meningitidis (2 group B; 6 group C) were analyzed for neuraminidase production and no enzymatic activity was detected. Each of the 27 strains of pneumococci was found to secrete neuraminidase and aldolase into the culture medium which contained from $1.3 \times 10^{5}$ to 1.3 $\times 10^{8}$ colony forming units per milliliter after $16 \mathrm{hr}$. Aldolase activity, expressed as micromoles $N$-acetyl-D-

\footnotetext{
${ }^{4}$ Generously provided by Dr. Stuart Tanenbaum.
} 


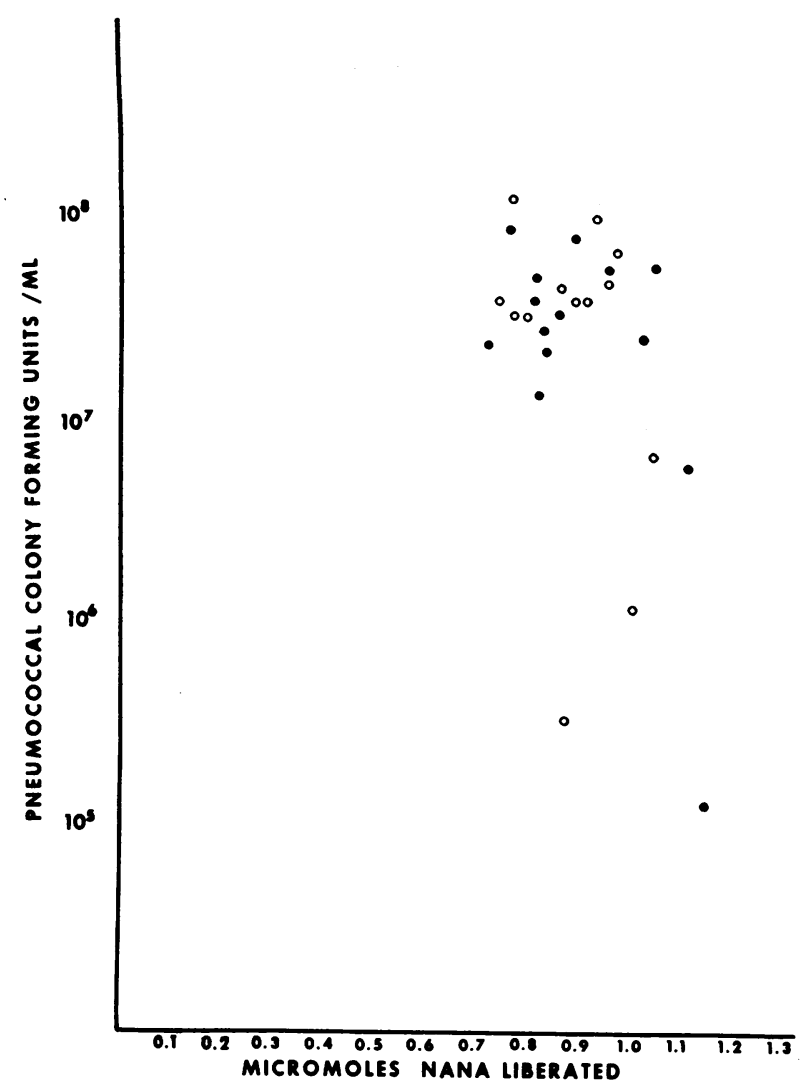

FIGURE 1 NANA liberation by separate strains of pneumococci. Open circles denote strains from patients cured. The distribution of serologic types was I (17), II (2), III (1), V (1), VI (1), XII (1), XVIII (2), XIX (1), XXXIII (1).

mannosamine detected per micromole of total NANA liberated (NANA plus $N$-acetyl-D-mannosamine), ranged from 1.5 to $14.7 \%$ with a mean of $6.0 \pm 3.1 \%$. The relationship between colony-forming units and micromoles of total NANA liberated is illustrated in Fig. 1. Also indicated is the clinical outcome of each corresponding patient. Under the conditions of the assay, there was no coorrelatin between cure or serologic type and quantity of enzyme elaborated.

CSF NANA Concentrations. On the supposition that pneumococci multiplying in the CSF and meninges would produce neuraminidase, which in turn would act upon glycoproteins and gangliosides present, free and total NANA in each sample of spinal fluid were measured (Table I). Total NANA levels were elevated for each type of bacterial meningitis.

Free and total CSF concentrations are depicted in Fig 2 for each patient studied. Significantly elevated values for free CSF NANA concentrations (mean control value plus $2 \mathrm{sD}=0.81 \mathrm{mg} / 100 \mathrm{ml}$ ) were detected in 17 of 35 patients with acute pneumococcal meningitis
TABLE I

CSF NANA Concentrations

\begin{tabular}{|c|c|c|c|}
\hline \multirow[b]{2}{*}{ Diagnosis } & \multirow[b]{2}{*}{ Patients } & \multicolumn{2}{|c|}{ NANA } \\
\hline & & Free & Total \\
\hline & & \multicolumn{2}{|c|}{$m g / 100 m l$} \\
\hline Control group & 28 & $0.37 \pm 0.22 *$ & $1.20 \pm 0.57$ \\
\hline $\begin{array}{l}\text { Acute pneumococcal } \\
\text { meningitis }\end{array}$ & 35 & $1.42 \pm 1.86$ & $6.13 \pm 4.31$ \\
\hline $\begin{array}{l}\text { Convalescent pneumococcal } \\
\text { meningitis } \ddagger\end{array}$ & 18 & $0.44 \pm 0.20$ & $1.56 \pm 0.67$ \\
\hline Meningococcal meningitis & 18 & $0.34 \pm 0.11$ & $4.55 \pm 2.42$ \\
\hline H. influenzae meningitis & 10 & $0.25 \pm 0.20$ & $3.44 \pm 1.25$ \\
\hline
\end{tabular}

* Mean \pm SD.

$\$ 12-14$ days after initiation of therapy.

and in 1 control patient; a $4 \mathrm{yr}$ old boy with communicating hydrocephalus. Patients with $H$. influenzae meningitis and meningococcal meningitis had normal free CSF NANA levels.

11 of 18 patients (61\%) with pneumococcal meningitis and normal free NANA levels were cured, whereas only 4 of 17 patients $(24 \%)$ with elevated values survived without residua $(P<0.10)$. Pneumonia, coma, and bacteremia were observed more often among pa-

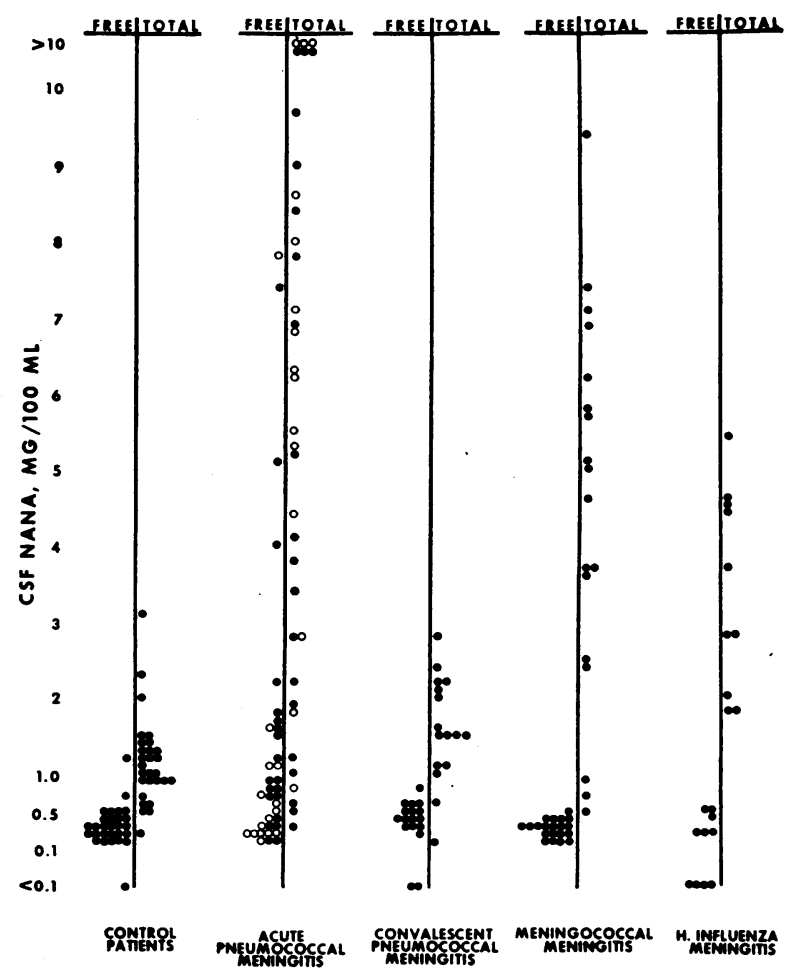

FIgURE 2 Free and total CSF NANA concentrations in acute bacterial meningitis. Open circles denote pneumococcal meningitis patients cured. 
TABLE II

Distribution of Prognostically Important Clinical Findings in 35 Patients with Pneumococcal Meningitis

\begin{tabular}{|c|c|c|c|c|}
\hline \multirow{2}{*}{$\begin{array}{l}\text { Clinical } \\
\text { finding }\end{array}$} & \multicolumn{2}{|c|}{$\begin{array}{l}\text { Normal free CSF } \\
\text { NANA levels } \\
\text { (18 patients) }\end{array}$} & \multicolumn{2}{|c|}{$\begin{array}{c}\text { Elevated free CSF } \\
\text { NANA levels } \\
\text { (17 patients) }\end{array}$} \\
\hline & Patients & Per cent & Patients & Per cent \\
\hline Coma & $3^{*}$ & 17 & $10^{*}$ & 59 \\
\hline Pneumonia & $4 \ddagger$ & 22 & $9 \ddagger$ & 53 \\
\hline Bacteremia & $4 \S$ & 22 & $13 \S$ & 77 \\
\hline
\end{tabular}

$* P<0.05$.

$\ddagger P<0.20$.

$\S P<0.01$.

tients with elevated than with normal free CSF NANA values (Table II).

Rates of change toward normal for both free and total NANA concentrations are plotted in Fig. 3. Included are all patients with pneumococcal meningitis, not cured, for whom any convalescent specimens were available (seven patients), and eight patients, who survived without residua, from whom at least three convalescent CSF samples were obtained. All convalescent specimens tested had normal free NANA levels even
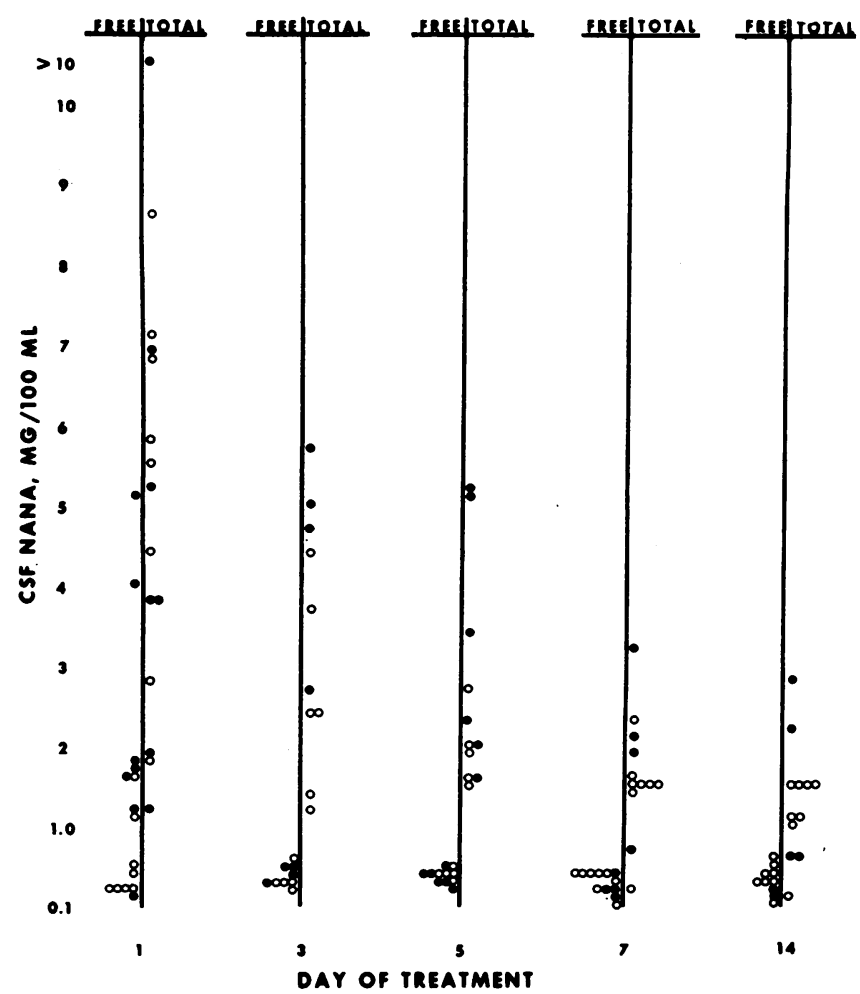

\section{.}

Fewer patients in the low range manifested coma $(24 \%)$ than in the high $(55 \%)$, and cure was more common among those in the $0-30 \%$ free group $(57 \%)$ than in those with $71-100 \%$ free/total ratio $(18 \%)(P<0.10)$.

Enzyme inhibition. Sufficient purified enzyme was available for analysis of acute CSF and serum from several patients with pneumococcal meningitis. Enzymeinhibiting activity was clearly present in both serum and spinal fluid of three patients (Table IV). Serum titers rose significantly during the course of each patient's illness. One CSF sample showed a slight rise after 7 days in hospital and two others fell significantly at a time when serum levels were highest. The increased titers of serum activity noted during convalescence and the associated drop in CSF titers, during the period of restoration of the blood-CSF barrier to normal, suggested that enzyme inhibitory activity was associated with humoral antibody.

\section{DISCUSSION}

Every strain of pneumococcus isolated from a patient with meningitis produced readily detectable amounts of neuraminidase. None of the strains of meningococci or $H$. influenzae secreted detectable enzyme. The number of isolates examined was small; however, each was freshly cultured from infected cerebrospinal fluid which contains the enzyme's substrate and which, therefore, may be con-

FIgURE 3 Free and total CSF NANA concentrations in pneumococcal meningitis. Open circles denote patients cured. 


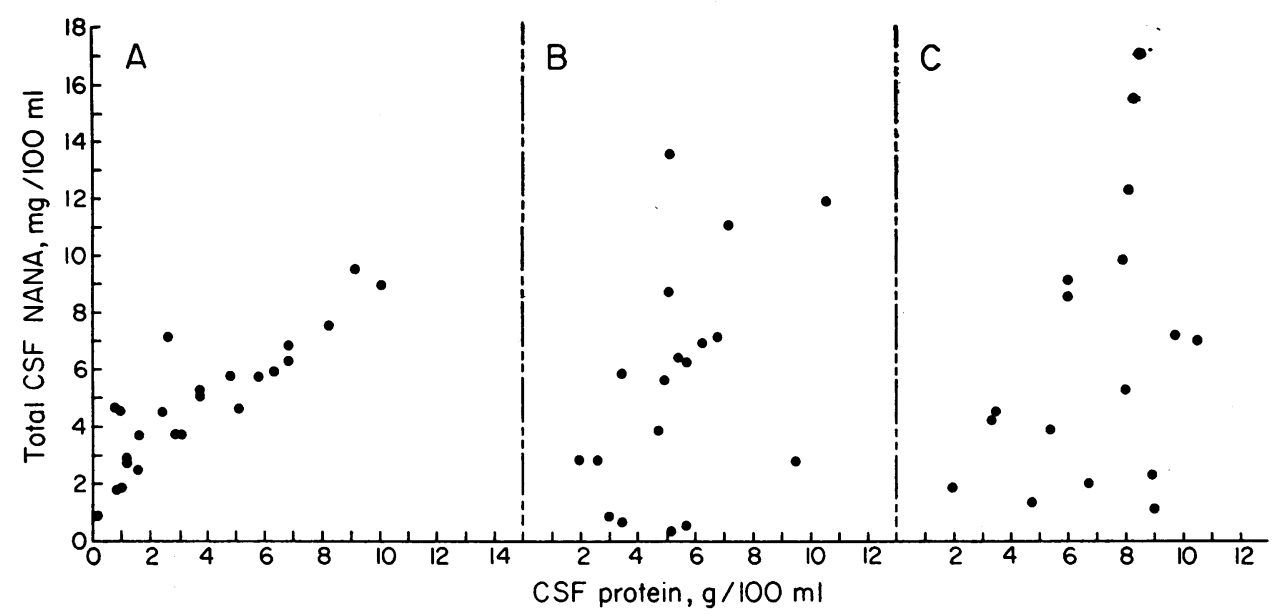

FIgURE $4 a$ Total CSF NANA and CSF protein concentrations in patients with meningococcal and $H$. influenzae meningitis. $r=0.79 ; P<0.001$.

FIgure $4 b$ Total CSF NANA and CSF protein concentrations in patients with pneumococcal meningitis and normal free CSF NANA concentrations. $r=0.61 ; P<0.01$.

Figure $4 c$ Total CSF NANA and CSF protein concentrations in patients with pneumococcal meningitis and elevated free CSF NANA concentrations. $r=0.38 ; P<0.20$.

sidered an excellent medium for the cultivation of enzyme-elaborating bacteria. Although the responsible organism was not analyzed for enzyme activity in every case of meningococcal meningitis, none of the cerebrospinal fluids from patients with meningococcal or $H$. influenzae meningitis showed elevated levels of free NANA, the split product of the enzyme's action. These observations suggest that neuraminidase is not secreted by meningococci or by $H$. influenzae.

NANA value derived from the CSF of our 28 control patients were in good agreement with the normal values given for free $(0.42 \pm 0.14 \mathrm{mg} / 100 \mathrm{ml})$ and total $(1.16$ $\pm 0.52 \mathrm{mg} / 100 \mathrm{ml}$ ) CSF NANA by Jakoby and Warren (11). These investigators examined CSF from $170 \mathrm{pa}-$

TABLE III

Per Cent NANA Liberated in CSF of 35 Patients with Acute Pneumococcal Meningitis

\begin{tabular}{crcc}
\hline $\begin{array}{c}\text { NANA liberated } \\
\text { (free/total) }\end{array}$ & Patients & Coma & Cured \\
\hline$\%$ & 14 & 2 & 9 \\
$0-10$ & 6 & 3 & 2 \\
$11-20$ & 1 & 0 & 1 \\
$21-30$ & 0 & & \\
$31-40$ & 2 & 1 & 1 \\
$41-50$ & 1 & 1 & 0 \\
$51-60$ & 0 & & \\
$61-70$ & 2 & 1 & 0 \\
$71-80$ & 5 & 3 & 1 \\
$81-90$ & 4 & 2 & 1 \\
$91-100$ & & & \\
\hline
\end{tabular}

tients and detected significantly elevated values only for total NANA. These occurred in eight patients with meningitis of unspecified etiology and in one patient with spinal block. They detected no correlation between total CSF protein concentrations and free or total NANA levels. This lack of correlation may have existed for the few patients in our study with meningitis and normal or slightly elevated protein concentrations. However, the obvious correlation between protein and total NANA observed at higher protein concentrations in CSF infected by nonneuraminidase-producing bacteria (Fig. $4 a$ ) suggests that serum glycoproteins present in infected CSF $(15,16)$ may comprise a major substrate for neuraminidase. This observation is supported by the work of Muller who has detected abnormal patterns of electrophoretic migration of serum glycoproteins in the

TABLE IV

Acute and Convalescent Titers of Neuraminidase Inhibition by CSF and Serum from Three Patients with Pneumococcal Meningitis

\begin{tabular}{|c|c|c|c|c|c|c|}
\hline \multirow[b]{2}{*}{ Patient } & \multirow[b]{2}{*}{ Sample } & \multicolumn{4}{|c|}{ Day of treatment } & \multirow[b]{2}{*}{ Outcome } \\
\hline & & 1 & 7 & 13 & 19 & \\
\hline 92 & $\begin{array}{l}\text { CSF } \\
\text { Serum }\end{array}$ & $\begin{array}{c}5^{*} \\
20\end{array}$ & $\begin{array}{r}40 \\
625\end{array}$ & & & Died day 12 \\
\hline 69 & $\begin{array}{l}\text { CSF } \\
\text { Serum }\end{array}$ & $\begin{array}{l}160 \\
625\end{array}$ & & $\begin{array}{r}0 \\
1280\end{array}$ & & $\begin{array}{c}\text { Severe residual } \\
\text { dementia }\end{array}$ \\
\hline 91 & $\begin{array}{l}\text { CSF } \\
\text { Serum }\end{array}$ & $\begin{array}{l}160 \\
640\end{array}$ & & & $\begin{array}{r}10 \\
3125\end{array}$ & Cured „ \\
\hline
\end{tabular}

* Reciprocal of dilution.

Neuraminidase Activity in Bacterial Meningitis 
CSF of a child with pneumococcal meningitis and an elevated CSF concentration of free NANA (17).

Neurons contiguous with the meninges and bathed in infected CSF may constitute another substrate for neuraminidase and source of CSF NANA. These cells are rich in NANA-bearing glycoproteins and gangliosides (18). The capacity of neuraminidase to liberate NANA from slices of brain cortex in vitro (19) raises the question of similar activity in vivo. The breakdown of the correlation between total NANA and CSF protein concentrations observed in patients with pneumococcal meningitis and evidence of neuraminidase activity (Fig. $4 c$ ) provides inferential evidence that such activity occurs. Specifically, the very high ratio of total NANA to protein concentrations observed in certain patients can best be explained by postulating a source for free NANA in addition to that provided by serum glycoproteins in CSF.

It is not possible to explain fully the unusually low total NANA/protein concentration ratios observed in the infected CSF of some patients (Fig. $4 c$ ) ; however, a high degree of aldolase activity may be partially accountable. In addition, free NANA may be more rapidly cleared from the subarachnoid space than that which is bound. Free NANA, as a low molecular weight amino sugar, may enter into pathways similar to those responsible for regulation of CSF glucose concentrations (20) whereas bound NANA may be removed largely by bulk flow through arachnoid granulations with other particulate and macromolecular substances (21).

In view of enzyme activity at the neuronal level implicated in this study, one is tempted to explain the high incidence of coma and adverse prognosis observed among patients with evidence of neuraminidase activity by assigning a causal role to neuraminidase. This relationship has been proposed by Kelly and Greiff who found the intracerebral injection of purified pneumococcal neuraminidase to be lethal for weanling mice (22); however, this hypothesis cannot be tested with absolute confidence by analysis of pneumococcal meningitis in man because of the interdependence of factors affecting survival. Review of our cases and those of others (23-26) indicates that coma, bacteremia, and pneumonia are all associated with an adverse prognosis, and all but coma and, perhaps, pneumonia presumably exert their ill effects independently of neuraminidase activity. In our study, pneumonia, coma, and bacteremia were also associated with elevated free CSF NANA concentrations. Elevated CSF NANA levels cannot, therefore, be related to coma or death per se, because most of these patients also had pneumonia or bacteremia. The question of the pathogenicity of neuraminidase for man must be resolved by study of the enzyme's effects in an appropriate animal model.

\section{ACKNOWLEDGMENTS}

We wish to thank Dr. Robert Austrian for helpful comments in preparation of the manuscript and Dr. Robert Petersdorf for advice in performance of the studies and critical review of the manuscript. We are indebted to Elaine Nyuha for technical assistance.

This work was supported by the Veterans Administration Research Associate Program (Dr. O’Toole).

\section{REFERENCES}

1. Kelly, R. T., S. Farmer, and D. Greiff. 1967. Neuraminidase activities of clinical isolates of Diplococcus pneumoniae. J. Bacteriol 94: 272.

2. Lee, L. T., and C. Howe. 1966. Pneumococcal neuraminidase. J. Bacteriol. 91 : 1418.

3. Hughes, R. C., and R. W. Jeanloz. 1964. The extracellular glycosidases of Diplococcus pneumoniae. I. Purification and properties of a neuraminidase and a betagalactosidase. Biochemistry. 3: 1535.

4. Hughes, R. C., and R. W. Jeanloz. 1964. The extracellular glycosidases of Diplococcus pneumoniae. II. Purification and properties of a beta- $\mathrm{N}$-acetylglucosaminidase. Biochemistry. 3: 1543.

5. Rafelson, M. E. 1963. The neuraminidases and their action on glycoproteins and other sialic acid-containing compounds. Exposes. Annu. Biochim. Med. 24: 121.

6. Brunngraber, E. G. 1969. The possible role of glycoproteins in neural function. Perspect. Biol. Med. (Spring) 12: 467 .

7. Kelly, R. T., D. Greiff, and S. Farmer. 1966. Neuraminidase activity in Diplococcus pneumoniae. J. Bacteriol. 91: 601.

8. Thornton, G. F., R. D. O'Toole, M. K. Mukherjee, and R. L. Nath. 1968. Adrenocorticosteroids in the treatment of pneumococcal meningitis. Clin. Res. 16: 335.

9. Warren, L. 1959. The thiobarbituric acid assay of sialic acids. J. Biol. Chem. $234: 1971$.

10. Brunetti, P., G. W. Jourdian, and S. Roseman. 1962 The sialic acids. III. Distribution and properties of animal $N$-acetylneuraminic acid aldolase. J. Biol. Chem. 237: 2447.

11. Jakoby, R. K., and L. Warren. 1961. Identification and quantitation of $\mathrm{N}$-acetylneuraminic acid in human cerebrospinal fluid. Neurology. 11: 232.

12. Snedecor, G. W., and W. G. Cochran. 1967. Statistical Methods. Iowa State University Press, Ames, Iowa 6th edition.

13. Tanenbaum, S. W., J. Gulbinsky, M. Katz, and S. C. Sun. 1970. Separation, purification and some properties of pneumococcal neuraminidase isoenzymes. Biochim. Biophys. Acta 198: 242.

14. Howe, C., L. T. Lee, and H. M. Rose. 1961. Collocalia mucoid: A substrate for myxovirus neuraminidase. Arch. Biochem. Biophys. 95: 512 .

15. Ursing, B. 1965. Clinical and immunoelectrophoretic studies on cerebrospinal fluid in virus meningoencephalitis and bacterial meningitis. Acta Med. Scand. Suppl. 429: 7 .

16. Schultze, H. E., and J. F. Heremans. 1966. Molecular Biology of Human Proteins. American Elsevier Publishing Co., Inc. New York. 1st edition. 732. 
17. Muller, H. E. 1969. Die neuraminidase als pathogenetischer faktor bei pneumokokken-infectionen. Deut. Med. Wochenschr. 94: 2149.

18. McIlwain, H. 1966. Biochemistry and the Central Nervous System. Little, Brown and Company, Boston, Mass. 3rd edition. 230.

19. Evans, W. H., and H. McIlwain. 1967. Excitability and ion content of cerebral tissues treated with alkylating agents, tetanus toxin, or a neuraminidase. J. Neurochem. $14: 35$.

20. Fishman, R. A. 1965. Carrier transport and the concentration of glucose in cerebrospinal fluid in meningeal diseases. Ann. Intern. Med. 63: 153.

21. Welch, K., and M. Pollay. 1961. Perfusion of particles through arachnoid villi of the monkey. Amer. J. Physiol. 201 : 651 .
22. Kelly, R., and D. Greiff. 1970. Toxicity of pneumococcal neuraminidase. Infect. Immun. 2: 115.

23. Carpenter, R. R., and R. G. Petersdorf. 1962. The clinical spectrum of bacterial meningitis. Amer. J. Med. 33: 262.

24. Quaade, E., and K. P. Kristensen. 1962. Purulent meningitis. Acta Med. Scand. 171: 543.

25. Swartz, M. N., and P. R. Dodge. 1965. Bacterial meningitis-a review of selected aspects. I. General clinical features, special problems and unusual meningeal reactions mimicking bacterial meningitis. N. Eng. J. Med. 272: 725, 779, 842.

26. Austrian, R. 1964. The role of toxemia and of neural injury in the outcome of pneumococcal meningitis. Amer. J. Med. Sci. $247: 257$. 